\title{
Brazilian Journal \\ of Chemical

\section{SCREENING OF STATIC CULTURE AND COMPARISON OF BATCH AND CONTINUOUS CULTURE FOR THE TEXTILE DYE BIOLOGICAL DECOLORIZATION BY Phanerochaete chrysosporium}

\author{
J. Urra, L. Sepúlveda, E. Contreras and C. Palma* \\ Department of Chemical Engineering, Fax: +(56) (02) 6817135, \\ University of Santiago de Chile, Alameda 3363. Santiago, Chile.
}

(Received: April 04, 2005 ; Accepted: May 05, 2006)

\begin{abstract}
The production of manganese dependent peroxidase (MnP) by Phanerochaete chrysosporium and the level of decolorization of 13 dyes were evaluated using static and agitated batch cultures and continuous cultures. A screening carried out under static conditions showed that the oxidative system has a certain affinity for azoic structures. For concentrations of $100 \mathrm{mg} \mathrm{l}^{-1}$ of Acid Black 1, Reactive Black 5, Reactive Orange 16 and Acid Red 27, decolorization percentages higher than 90\% were obtained. In batch cultures with Acid Black 1 and Reactive Black 5 a significant increment in primary post-metabolism biomass was observed. For these last two dyes, it was possible to explore the response of the continuous system during 32 to 47 days, with concentrations between 25 to $400 \mathrm{mg} \mathrm{l}^{-1}$, obtaining decolorization percentages greater than $70 \%$ for $400 \mathrm{mg} \mathrm{l}^{-1}$. Keywords: Biological decolorization; Dyes; Fixed bed bioreactor; Manganese dependent peroxidase.
\end{abstract}

\section{INTRODUCTION}

The generation of colored wastewaters is a reality for a variety of industrial sectors. Among these residues are effluents arising from textile and printing processes, drycleaners and tanneries, the food industry, manufacture of paints and varnishes, manufacture of plastics and a variety of chemical processes. Commercial dyes have a great variety of colors, and a high stability to light, temperature, detergents and microbial attack.

The most often used processes for the color removal are based on chemical or physical-chemical treatments all of which have certain disadvantages. Physical-chemical treatments which include membrane filtration, coagulation-flocculation, ion exchange, adsorption, electroflotation, precipitation, ultrafiltration and reverse osmosis, all have the disadvantage that the contaminant is not destroyed, it is simply concentrated and subsequently deposited in sanitary landfills or incinerated (Bertchtold et al., 2001).

The decolorization of effluents by biological processes has been extensively investigated. These effluents are usually treated by conventional aerobic and anaerobic methods, which reduce the chemical oxygen demand (COD) and the biological oxygen demand (BOD), but are not efficient in reducing color. Some microorganisms including bacteria, fungi and algae, can degrade or adsorb a wide range of dyes (Kirby et al., 1995; Robinson et al., 2001). The adsorption of colored contaminants onto the biomass (Yang et al., 2003; Zhang et al., 2003) is of limited value if the final objective is the destruction

*To whom correspondence should be addressed 
of the molecule (O’Neill et al., 1999, BromleyChallenor et al., 2000).

Numerous studies report the application of degradation processes on a large variety of effluents and recalcitrant compounds through the action of white-rot fungi by means of a highly oxidative, nonspecific, extracellular ligninolytic enzymatic system. This method has been presented as a viable alternative to the inherent limitations of conventional biological treatment processes.

This system is made up of various enzymes. Lignin peroxidase (LiP) and manganese peroxidase (MnP) were discovered in the mid-1980s in $P$. chrysosporium and described as true ligninases because of their high redox potential. LiP degrades non-phenolic lignin units (up to $90 \%$ of the polymer), whereas $\mathrm{MnP}$ generates $\mathrm{Mn}^{3+}$, which acts as a diffusible oxidizer on phenolic or non-phenolic lignin units via lipid peroxidation reactions. More recently, versatile peroxidase (VP) has been described in Pleurotus and other fungi as a third type of ligninolytic peroxidase that combines the catalytic properties of $\mathrm{LiP}, \mathrm{MnP}$, and plant/microbial peroxidases oxidizing phenolic compounds (Martínez et al., 2005).

In particular, $\mathrm{MnP}$ has been identified as being responsible for the decolorization of a variety of substrates including numerous dyes (Lopez et al., 2004; Mielgo et al., 2003; Moreira et al., 2001; Moreira et al., 2000). In this context, the purpose of the present study is the investigation of the behavior of the enzymatic system of the white-rot fungus, Phanerochaete chrysosporium, in a fixed bed bioreactor, as an alternative for the decolorization of a variety of dyes. Additionally, their application in static and agitated batch, and continuous culture systems was compared.

\section{MATERIALS AND METHODS}

\section{Microorganism}

Phanerochaete chrysosporium BKM-F-1767 (ATCC 24725) was kept at $4^{\circ} \mathrm{C}$ in malt extract plates (Mester et al., 1996).

\section{Assays}

\section{Static Culture}

Decolorization experiments were carried out statically in Erlenmeyer flasks (100 ml) covered with cotton and gauze stoppers, with 3 inoculating agar plugs (5 $\mathrm{mm}$ in diameter) transferred from maintenance plates, and $15 \mathrm{ml}$ of medium $\left(10 \mathrm{~g} \mathrm{l}^{-1}\right.$ of glucose, $2.2 \mathrm{mM}$ of ammonium tartrate and $100 \mathrm{ml} \mathrm{l}^{-1}$ of BIII mineral medium (Tien and Kirk, 1988) in

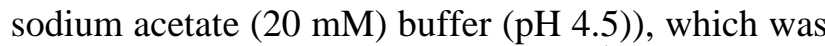
supplemented with 50 and $100 \mathrm{mg} \mathrm{l}^{-1}$ of dyes. The medium was autoclaved, and then a filter-sterilized thiamine solution (400 $\left.\mathrm{mg} \mathrm{l}^{-1}\right)$ was added $\left(5 \mathrm{ml} \mathrm{l}^{-1}\right)$. Biotic and abiotic controls were carried out in parallel. The biotic controls were formed by mycelium and culture medium, and abiotic controls consisted of water and culture medium supplemented with dye. All cultures (in triplicate) were incubated for 15 days at $37^{\circ} \mathrm{C}$ in an air atmosphere with $100 \%$ relative humidity.

\section{Agitated culture}

The pre-inoculate was prepared in a Fernsbatch (2 l) which contained $10-12$ plugs (5 $\mathrm{mm}$ in diameter) as an inoculate with $100 \mathrm{ml}$ of culture medium, and was incubated at $37^{\circ} \mathrm{C}$ for $2 \mathrm{~d}$. The medium was made up of $10 \mathrm{~g} \mathrm{l}^{-1}$ of glucose, $2.2 \mathrm{mM}$ of ammonium tartrate, and $100 \mathrm{ml} \mathrm{l}^{-1}$ of BIII mineral medium (Tien and Kirk, 1988) in sodium acetate (20 $\mathrm{mM}$ ) buffer ( $\mathrm{pH} 4.5$ ). The medium was autoclaved and then a filter-sterilized thiamine solution $(400 \mathrm{mg}$ $\mathrm{l}^{-1}$ ) was added $\left(5 \mathrm{ml} \mathrm{l}^{-1}\right)$. The mycelium that formed on the surface was homogenized and inoculated in a $10 \%(\mathrm{v} / \mathrm{v})$ proportion in Erlenmeyer flasks $(250 \mathrm{ml})$ which contained $81 \mathrm{ml}$ of culture medium (described above), supplemented with $100 \mathrm{mg} \mathrm{l}^{-1}$ of dyes. Biotic and abiotic controls were carried out in parallel. The biotic controls were formed by mycelium and culture medium; abiotic controls consisted of water and culture medium supplemented with dye. All cultures (in triplicate) were incubated at $37^{\circ} \mathrm{C}$ in an orbital agitator (at $1 \times \mathrm{g}$ ). After inoculation and then every $24 \mathrm{~h}$, the cultures were oxygenated with pure $\mathrm{O}_{2}$ for 3 min using a pressure of 0.8 bar. The flasks were kept stoppered with rubber plugs in order to maintain the oxygen atmosphere.

\section{Immobilization}

The support for immobilization consisted of polyurethane foam cubes of $0.125 \mathrm{~cm}^{3}$ with a density of $20 \mathrm{~kg} \mathrm{~m}^{-3}$. The immobilization process was carried out in Erlenmeyer flasks $(250 \mathrm{ml})$ which contained medium and inoculate in equal proportions to that used in the agitated cultures, and $1.8 \mathrm{~g}$ of foam. After 3 or 4 days two Erlenmeyer flasks with the colonized foam were transferred as inoculate to the bioreactor. 


\section{Equipment and Operating Conditions of the Bioreactors}

The design of the bioreactor consisted of a double walled glass column, with an internal diameter of 4.5 $\mathrm{cm}$ and a height of $20 \mathrm{~cm}$, with an effective volume of $203 \mathrm{ml}$. The system was oxygenated by a pulsed flow of gaseous $\mathrm{O}_{2}$ applied with a frequency of $0.0625 \mathrm{~s}^{-1}$. Temperature was kept at $37^{\circ} \mathrm{C}$ by circulating hot water between the walls of the bioreactor. The column was operated with an ascending input flow and a hydraulic residence time (HRT) of $24 \mathrm{~h}$. The culture medium was as described by Palma et al., 1999. Samples were taken from the culture media twice daily at three axially distributed points in the columns during the entire operation period. The make up of the input flow was as described by Tien and Kirk (1988). The addition of the different dyes was carried out in a programmed fashion with rising concentration steps from 25 to $400 \mathrm{mg} \mathrm{l}^{-1}$.

\section{Enzyme Activity}

Enzymatic activities were determined spectrophotometrically at $30^{\circ} \mathrm{C}$. Manganese peroxidase was determined by monitoring the oxidation of 2,6-dimethoxyphenol (DMP). The reaction mixture for manganese peroxidase contained $50 \mathrm{mM}$ of sodium malonate $(\mathrm{pH} 4.5), 1$ $\mathrm{mM}$ of 2,6-dimethoxyphenol (DMP), $1 \mathrm{mM}$ of $\mathrm{MnSO}_{4}$, and up to $600 \mathrm{~mL}$ of supernatant in a total volume of $1 \mathrm{~mL}$. The reaction was initiated by adding $0.4 \mathrm{mM}$ of $\mathrm{H}_{2} \mathrm{O}_{2}$ and corrected for laccase (activity prior to adding $\mathrm{H}_{2} \mathrm{O}_{2}$ ) and manganeseindependent peroxidase (MIP) activity (Field et al., 1992). LiP activity was assayed against veratryl alcohol as described by Tien and Kirk (1988).

\section{Analytical Assays}

Whole pellet-cultures were filtered through glassfiber filters (Whatman, GF/C, $\varnothing 42 \mathrm{~mm}$ ) and mycelial dry-weights were determined after $24 \mathrm{~h}$ drying at $105^{\circ} \mathrm{C}$. The decolorization of dyes was monitored by the reduction in absorbance at characteristic wavelength (Table 1). Before the absorbance readings, $0.2 \mathrm{ml}$ of centrifuged sample $(9,000 \times \mathrm{g}$, for $10 \mathrm{~min})$ was diluted with $0.8 \mathrm{ml}$ distilled water.

\section{Dyes}

The dyes selected for the study, were of analytic grade and provided by Sigma S.A.. The dyes and their characteristics are presented in Table 1.

Table 1: Characteristics of dyes.

\begin{tabular}{|c|c|c|c|}
\hline Dye & Chromophore & $\lambda(\mathbf{n m})$ & Structure \\
\hline Acid Black 1 (AB1) & Diazo & 618.5 & \\
\hline Acid Red 27 (AR27) & Azo & 522.5 & \\
\hline Acid Orange 6 (AO6) & Azo & 390.0 & \\
\hline Basic Blue 3 (BB3) & Oxazine & 654.5 & \\
\hline Basic Blue 24 (BB24) & Thiazine & 633.0 & \\
\hline Basic Blue 41 (BB41) & Azo & 617.0 & \\
\hline Basic Green 4 (BG4) & Triphenylmethane & 615.5 & \\
\hline Basic Orange 2 (BO2) & Azo & 454.0 & \\
\hline
\end{tabular}


Continuation Table 1

Table 1: Characteristics of dyes.

\begin{tabular}{|c|c|c|c|}
\hline Dye & Chromophore & $\lambda(\mathrm{nm})$ & Structure \\
\hline Basic Violet 4 (BV4) & Triphenylmethane & 595.0 & \\
\hline Poly R-478 (PR478) & Anthraquinone & $520 / 350$ & \\
\hline Reactive Black 5 (RB5) & Diazo & 597.5 & \\
\hline Reactive Blue 19 (RB19) & Anthraquinone & 592.5 & \\
\hline Reactive Orange 16 (RO16) & Azo & 493.0 & \\
\hline
\end{tabular}

\section{RESULTS AND DISCUSSION}

\section{Static Culture}

In order to evaluate the degrading capacity of the MnP enzyme produced by Phanerochaete chrysosporium during secondary metabolism, dyes with an azoic structure were selected by preference (Table 1). These dyes represent the most prevalent group of synthetic dyes in textile, food, printing, cosmetic, pharmaceutical and paper industries among others.

By using the screening method developed, it was determined that the fungus has a capacity for partial or total decolorization of the selected dyes. For AB1, RB5, RO16 and AR27 dyes, in whose structure the azoic group is joined to benzene-naphthalene rings as well as naphthalene-naphthalene rings, a high percentage of decolorization (above 90\%) was obtained (Table 2). These also have in common the presence of sulphonic, $\mathrm{N}$-alkyl and hydroxyl auxochrome groups, which are characteristic of acid and reactive dyes. Azoic dyes with two benzene rings show lower percentages of decolorization (BO2 and AO6).

Dyes with a triphenylmethane structure such as BG4 and BV4, are not degraded by the fungus. For the former an adsorption phenomenon was observed while for the latter an inhibition of growth was recorded. Both phenomena have been reported, and one of the most often used decolorization techniques for these dyes is precisely adsorption on biomass (Sani and Banerjee, 1999; Knapp et al., 2001).

The present study was not conclusive with respect to the rest of the structures analyzed (thiazine, oxacine and anthraquinones). Even though these have a marked effect on biodegradability, the relationship between the two has not been established. Nonetheless, it has been pointed out that the number, position and type of functional groups are determinant in the process of decolorization (Spadaro et al., 1992; Martins et al., 2002). 
Table 2: Decolorization in static culture

\begin{tabular}{|c|c|c|c|}
\hline Dye & Concentration $\left(\mathrm{mg} \mathrm{l}^{-1}\right)$ & Period (d) & Decolorization (\%) \\
\hline \multirow{2}{*}{$\mathrm{AB} 1$} & 50 & 15 & $98.7 \pm 1.4$ \\
\hline & 100 & 15 & $99.1 \pm 0.6$ \\
\hline \multirow{2}{*}{ AR27 } & 50 & 12 & $98.5 \pm 1.1$ \\
\hline & 100 & 13 & $96.9 \pm 3.6$ \\
\hline \multirow{2}{*}{ RB5 } & 50 & 9 & $95.3 \pm 0.8$ \\
\hline & 100 & 12 & $97.5 \pm 0.6$ \\
\hline \multirow{2}{*}{ RO16 } & 50 & 15 & $93.8 \pm 2.5$ \\
\hline & 100 & 15 & $91.6 \pm 4.8$ \\
\hline \multirow{2}{*}{ BB41 } & 50 & 5 & $96.7 \pm 1.1$ \\
\hline & 100 & 9 & $84.3 \pm 0.2$ \\
\hline \multirow{2}{*}{ BB24 } & 50 & 15 & $97.0 \pm 2.9$ \\
\hline & 100 & 15 & $74.6 \pm 4.6$ \\
\hline \multirow{2}{*}{$\mathrm{BO} 2$} & 50 & 15 & $65.5 \pm 33.4$ \\
\hline & 100 & 15 & $39.5 \pm 3.6$ \\
\hline \multirow{2}{*}{ PR478 } & 50 & 15 & $58.5 \pm 1.5$ \\
\hline & 100 & 15 & $54.2 \pm 1.3$ \\
\hline \multirow{2}{*}{ AO6 } & 50 & 15 & $58.5 \pm 30.0$ \\
\hline & 100 & 15 & $6.9 \pm 1.2$ \\
\hline \multirow{2}{*}{ RB19 } & 50 & 15 & $20.1 \pm 28.4$ \\
\hline & 100 & 15 & $30.7 \pm 7.9$ \\
\hline \multirow{2}{*}{ BG4 } & 50 & 15 & $17.3 \pm 7.3$ \\
\hline & 100 & 15 & $20.1 \pm 2.5$ \\
\hline \multirow{2}{*}{ BB3 } & 50 & 15 & ND \\
\hline & 100 & 15 & ND \\
\hline \multirow{2}{*}{ BV4 } & 50 & 15 & ND \\
\hline & 100 & 15 & ND \\
\hline
\end{tabular}

ND: Not Detected decolorization

\section{Agitated Culture}

Figure 1 summarizes the principal observed effects on agitated cultures which were carried out for the following azoic dyes: AB1, RB5 and RO16. The principal biological decolorization mechanisms identified are biomass adsorption and biodegradation. Figure 1a shows the percentages of adsorption and color removal at the end of the experiments. The process of adsorption of color onto the mycelium occurs during primary metabolism; after this period the assumption is that the ligninolytic system is responsible for color removal. No residual color was observed on the biomass at the end of the test. This suggests that the dyes are degraded by the oxidative action of the MnP present in the medium, ( $\mathrm{LiP}$ was not detected in the cultures). Previous studies show that the process of adsorption does not appear to be the predominant mechanism, but probably forms part of the global process. A synergistic effect has been observed between adsorption and subsequent biodegradation, caused by the extracellular ligninolytic system (Palma, 1998). This process is probably associated to the previous adsorption process by the mycelium as this permits a close contact between the chromophore group and the degrading enzymes which are associated to the surface of the hyphae (Evans et al., 1991; Yang et al., 2003).
Figure $1 \mathrm{~b}$ shows that in the batch culture with an alternative substrate there is an increment with respect to the control culture, both in biomass and in activity level. The increase in post secondary metabolism biomass indicates that there is nitrogen available for growth. This significant fact may be associated to the liberation of nitrogen from the azoic group during biodegradation thus increasing its presence in the basal media. Considering that whiterot fungi have the ability to use a large variety of sources of organic and inorganic nitrogen (Martínez et al., 1994; Mester et al., 1996), the increase in biomass is a sign of dye degradation.

This new growth stage implies a second phase in which nitrogen is limiting with the consequent rise in the activity of $\mathrm{MnP}$, surpassing in almost $400 \%$ the values registered in the biotic control. This effect, also observed by other authors (Palma, 1998; Yang et al., 2003), can be used for the degradation of dyes that inhibit primary metabolism in these fungi when added to media, once the secondary metabolism has begun as a product of the degradation of a labile substrate. In assays carried out by adding BV4 in pulses of increasing concentration (1, 2.5, 5 and 7.5 $\mathrm{mg} \mathrm{l}^{-1}$ ) to a medium which contains an excess of $\mathrm{MnP}$ as a result of the total degradation of $100 \mathrm{mg} \mathrm{l}^{-1}$ of $A B 1$, the enzymatic system degraded $100 \%$ of the triphenylmethane for the range of concentrations considered (data not shown). 


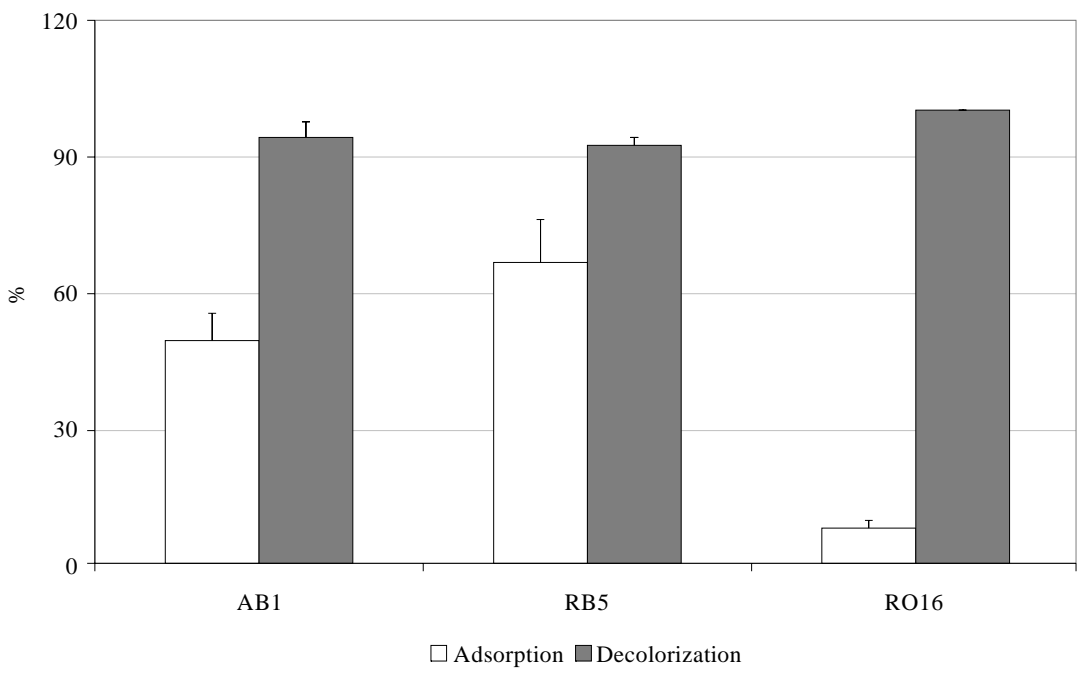

(a)

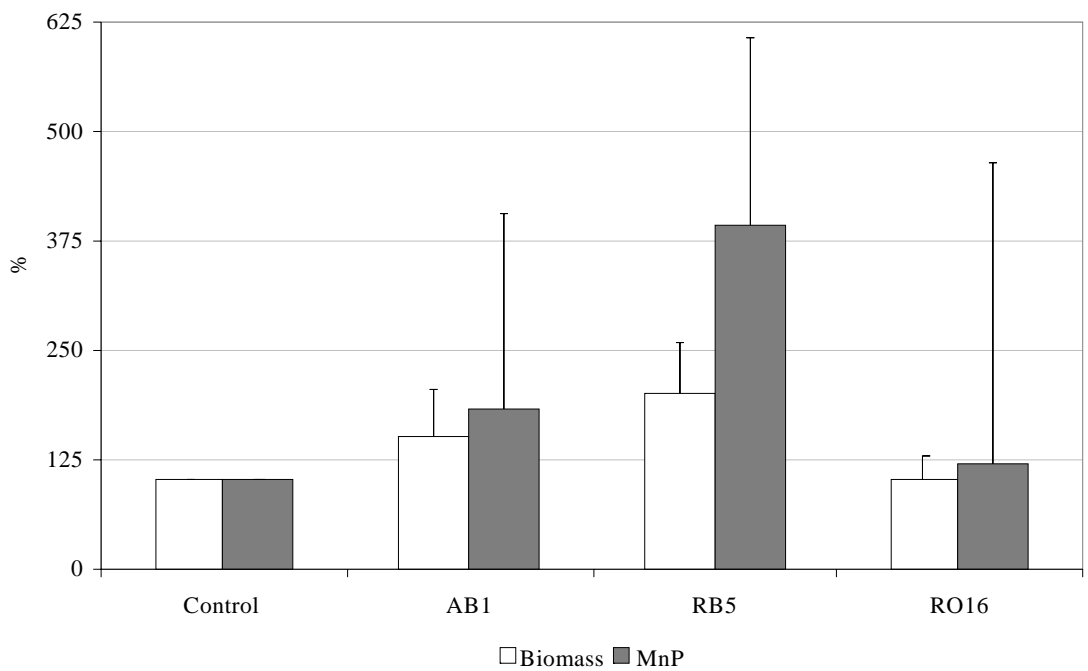

(b)

Figure 1: Decolorization in agitated culture. a) Percentage of adsorption during the primary metabolism and decolorization reached at the end of the experiment. b) Percentages, relative to the control, of biomass and $\mathrm{MnP}$ activity at the end of the experiments.

\section{Dye Decolorization in a Packed-Bed Bioreactor}

With the purpose of overcoming the limitations inherent in batch cultures, i.e. a restricted enzyme producing period, the present study analyzed a continuous decolorization system. This was done by means of a fixed bed bioreactor with immobilized biomass. The continuous production of this fungal enzyme is restricted by the physiological and morphological characteristics of the fungus. An unstable production of the enzyme during secondary metabolism, and an uncontrolled growth of the mycelium reduce the yield of the process after a short period of time (Moreira et al., 1995; 1997; 1998).

For the production of $\mathrm{MnP}$ in a continuous system with immobilized Phanerochaete chrysosporium these difficulties have been overcome by means of an oxygen feed with intermittent pulses and using a Nitrogen limited medium. With this strategy the fixed bed bioreactor was operated for periods in excess of 100 d (Moreira et al., 1997; 1998).

The purpose of a continuous assay is to evaluate the response of the system to increasing concentration steps for different dyes. The minimum 
period established for the change in concentration was determined by considering the evolution of the system until achievement of a steady state operation which corresponds to at least 4 times the HRT (24 h).

In trial runs the bioreactor was fed culture medium until a stable enzyme production was achieved (approximately $10 \mathrm{~d}$ ), subsequently the medium was supplemented with dyes. The effectiveness of the strategy was evaluated by determining decolorization profiles and the production of MnP. Figure 2 presents, by way of an example, the results achieved for the dye AB1.

The figure shows a high level of decolorization during the entire operational period of the bioreactor (approximately $35 \mathrm{~d}$ ) which remained stable in spite of long periods of low ligninolytic activity. These results coincide with those obtained by Palma et al. (1999).

The behavior of the activity levels shows the capacity of the fungus to adapt to increasing concentrations of the alternative substrate. For levels of $\mathrm{AB} 1$ concentrations of $400 \mathrm{mg} \mathrm{l}^{-1}$, the $\mathrm{MnP}$ production is interrupted and the decolorization percentage decreases.

Various authors have established that the presence of the $\mathrm{Mn}^{2+}$ ion is essential for inducing the production of $\mathrm{MnP}$ by means of the metabolic cycle of white-rot fungi (Bonnarme and Jeffries, 1990;
Brown et al., 1990; Mester et al., 1995). The concentration of $\mathrm{Mn}^{2+}$ which maximizes production of $\mathrm{MnP}$, in continuous cultures with immobilized biomass, is on the order of $5000 \mu \mathrm{M}$ (Moreira et al., 1997). The $\mathrm{Mn}^{2+}$ ion is also responsible for the closing of the catalytic cycle of this enzyme and its subsequent stabilization (Glenn et al., 1986; Wariishi et al., 1988; Palma et al., 1997). Considering the above, in those cases in which the activity of MnP decreased constantly, the culture medium was supplemented with Manganese, increasing the concentration to 2700 to $5000 \mu \mathrm{M}$ of $\mathrm{Mn}^{2+}$.

For the dye AB1 in particular (Table 3), this strategy was successful for a concentration of 200 $\mathrm{mg} \mathrm{l}^{-1}$, in which $2700 \mu \mathrm{M}$ of $\mathrm{Mn}^{2+}$ were used, achieving an increase in activity. However, at 400 $\mathrm{mg} \mathrm{l}^{-1}$ and the same concentration of $\mathrm{Mn}^{2+}$, the activity decreased constantly. The biological system is apparently inhibited by a high concentration of substrate annulling the possible inductive and protective effect of $\mathrm{Mn}^{2+}$.

Table 3 summarizes the results of decolorization and mean enzymatic activity obtained under different environmental conditions with the following dyes: AB1, BB41, RB5 and RO16. As can be observed, the dyes with a diazoic structure show the best response to the oxidative action of the enzyme.

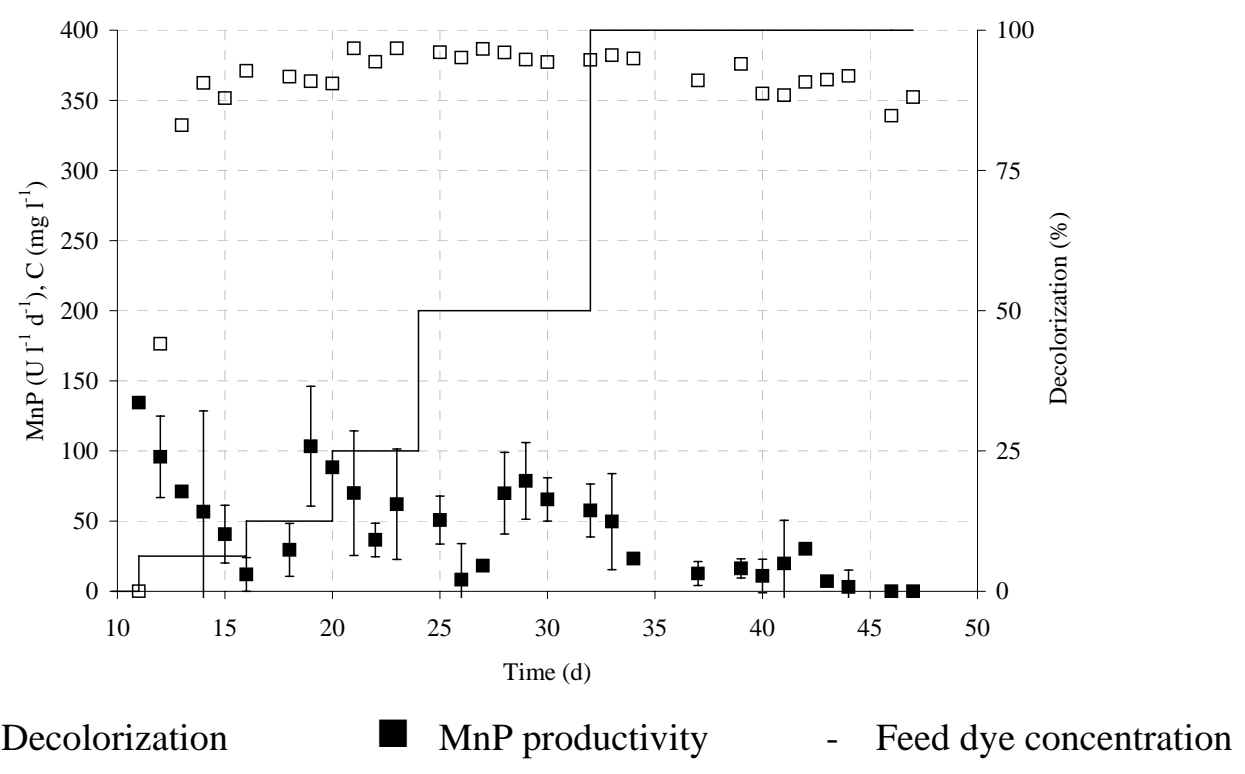

Figure 2: Acid Black 1 decolorization percentage and MnP productivity in a packed bed bioreactor. 
Table 3: Decolorization in continuous culture

\begin{tabular}{|c|c|c|c|c|c|}
\hline Dye & $\begin{array}{c}\text { Concentration } \\
\left(\mathrm{mg} \mathrm{I}^{-1}\right)\end{array}$ & $\begin{array}{l}\mathbf{M n}^{+2} \\
(\mu \mathrm{M})\end{array}$ & $\begin{array}{c}\mathrm{MnP} \\
\left(\mathrm{U} \mathrm{I}^{-1}\right)\end{array}$ & $\begin{array}{l}\text { Period } \\
\text { (d) }\end{array}$ & $\begin{array}{c}\text { Decolorization } \\
(\%)\end{array}$ \\
\hline \multirow{6}{*}{ AB1 } & 25 & 33 & 55 & 5 & 91 \\
\hline & 50 & 33 & 73 & 4 & 91 \\
\hline & 100 & 33 & 50 & 4 & 96 \\
\hline & 200 & 33 & 8 & 1 & 93 \\
\hline & 200 & 2700 & 52 & 8 & 95 \\
\hline & 400 & 2700 & 11 & 11 & 88 \\
\hline \multirow{5}{*}{ BB41 } & 25 & 33 & 75 & 4 & 96 \\
\hline & 50 & 33 & 106 & 4 & 98 \\
\hline & 100 & 33 & 59 & 6 & 94 \\
\hline & 100 & 2700 & 8 & 2 & 55 \\
\hline & 100 & 5000 & 0.5 & 2 & 50 \\
\hline \multirow{6}{*}{ RB5 } & 25 & 33 & 78 & 4 & 91 \\
\hline & 50 & 33 & 41 & 6 & 93 \\
\hline & 100 & 33 & 25 & 5 & 93 \\
\hline & 200 & 33 & 7 & 4 & 86 \\
\hline & 200 & 2700 & 23 & 8 & 79 \\
\hline & 400 & 5000 & 30 & 9 & 70 \\
\hline \multirow{5}{*}{ RO16 } & 25 & 33 & 57 & 6 & 92 \\
\hline & 50 & 33 & 48 & 5 & 92 \\
\hline & 100 & 33 & 31 & 4 & 92 \\
\hline & 200 & 33 & 29 & 10 & 92 \\
\hline & 400 & 2700 & 8 & 2 & 56 \\
\hline
\end{tabular}

\section{CONCLUSIONS}

With the proposed strategy for the evaluation and follow-up of the decolorization process some important aspects were identified. The screening using static cultures showed that the oxidative system has a certain degree of selectivity for azoic structures with naphthalene rings. In agitated cultures the existence of two synergistic mechanisms has been identified in the processes of decolorization, adsorption, and enzymatic degradation. Adsorption is only present during the initial phase and is neither the preponderant nor the final mechanism responsible for the decolorization. During the assays an excess of MnP was observed which causes a total degradation and assimilation of the analyzed substrates, in particular those with a diazo structure.

With respect to continuous culture, it was verified that the conditions established in prior studies for producing $\mathrm{MnP}$ are applicable as a decolorization strategy. Furthermore, the biological system is capable of responding satisfactorily to increasing concentration steps for various dyes, obtaining decolorization percentages greater than $70 \%$ for concentrations up to $400 \mathrm{mg} \mathrm{l}^{-1}$ (AB1 and RB5).

\section{ACKNOWLEDGEMENT}

This work was supported by FONDECYT 1040089.

\section{REFERENCES}

Bertchtold, T., Burtscher, E. and Turcam, A. (2001). Cathodic reduction of CI Acid Red 27 and CI Reactive Black 5. Basic Investigations of decolourisation of textile waste. Textile Research Journal, 71, 870.

Bonnarme, P. and Jeffries, T.W. (1990). Mn (II) regulation of lignin peroxidases and manganesedependent peroxidases from lignin-degrading white-rot fungi. Applied Environmental Microbiology, 56, 210.

Bromley-Challenor, K.C.A., Knapp, J.S., Zhang, Z., Gray, N.N.C., Hetheridge, M.J. and Evans, M.R. (2000). Decolorization of an azo dye by unacclimated activated sludge under anaerobic conditions. Water Research, 34, 4410.

Brown, J.A., Glenn, J.K. and Gold, M.H. (1990). Manganese regulates expression of manganese peroxidase by Phanerochaete chrysosporium. Journal Bacteriology, 172, 3125. 
Evans, C.S., Gallagher, I.M., Atkey, P.T. and Wood, D.A. (1991). Localization of degradative enzymes in white-rot decay of lignocellulose. Biodegradation, 2, 93.

Field, J.A., de Jong, E., Feijoo-Costa, G. and de Bont, J.A.M. (1992). Biodegradation of polycyclic aromatic hydrocarbons by new isolates of white-rot fungi. Applied Environmental Microbiology, 58, 2219.

Glenn, J.K. Akileswaran, L. and Gold, M.H. (1986). Mn (II) oxidation is the principal function of the extracellular Mn-peroxidase from Phanerochaete chrysosporium. Archives Biochemical Biophysical, 251, 688.

Knapp, J.S., Vantoch-Wood, E.J. and Zhang, F. (2001). Fungi in Bioremediation, Part 10: Use of wood-rotting fungi for the decolorization of dyes and industrial effluents. In: Gadd, G.M. (Ed). Cambrigde University Press.

Kirby, N., McMullan, G. and Marchant, R. (1995). Decolourisation of an artificial textile effluent by Phanerochaete chrysosporium. Biotechnology Letters, 17, 761.

Lopez, C., Moreira, M.T., Feijoo, G. and Lema, J.M. (2004). Dye decolorization by manganese peroxidase in an enzymatic membrane bioreactor. Biotechnology Progress, 20, 74.

Martínez, M.J., Ruiz, F.J. and Martínez, A.T. (1994). Influence of Mn concentration and $\mathrm{N}$ source on the production of ligninolytic enzymes in liquid cultures and $\mathrm{N}$ source on the production of ligninolytic enzymes in liquid cultures of Pleurotus species. Abs. $5^{\text {th }}$ Int. Mycol. Congr. Vancouver. August 14-21. 134.

Martínez, A. T., Speranza, M., Ruiz-Dueñas, F.J., Ferreira, P., Camarero, S., Guillén, F., Martínez, M.J., Gutiérrez, A. and del Río, J.C. (2005). Biodegradation of lignocellulosics: microbial, chemical, and enzymatic aspects of the fungal attack of lignin. International Microbiology, 8, 195.

Martins, M.A., Queiroz, M.J., Silvestre, A.J. and Lima, M. (2002). Relationships of chemical structures of textile dyes on the pre-adaptations medium and the potentialities of their degradation by Phanerochaete chrysosporium. Research Microbiology, 153, 361.

Mester, T., de Jong, E. and Field, J.A. (1995). Manganese regulation of veratryl alcohol in white rot fungi and its indirect effect on lignin peroxidase. Applied Environmental Microbiology, 61, 1881.

Mester, T., Peña, M. and Field, J.A. (1996). Nutrient regulation of extracellular peroxidases in the white-rot fungus, Bjerkandera sp. Strain BOS55. Applied Microbiology Biotechnology, 44, 778.

Mielgo, I., Lopez, C., Moreira, M.T., Feijoo, G. and Lema, J.M. (2003). Oxidative degradation of azo dye by manganese peroxidase under optimized conditions. Biotechnology Progress, 19, 25.

Moreira, M.T., Feijoo, G. and Lema, J.M. (1995). Production of manganese peroxidase by free pellets of Phanerochaete chrysosporium in an expanded bed bioreactor. Biotechnology Technology, 9, 371.

Moreira, M.T., Palma, C., Feijoo, G. and Lema, J.M. (1997). Decolorization of ion-exchange effluents derived from sugar-mill operations by Bjerkandera sp. BOS55. International Biodeterioration \& Biodegradation, 40, 125.

Moreira, M.T., Palma, C., Feijoo, G. and Lema, J.M. (1998). Strategies for the continuous production of ligninolytic enzymes in fixed and fluidised bed bioreactors. Journal Biotechnology, 66, 27.

Moreira, M.T., Mielgo, I., Feijoo, G. and Lema, J.M. (2000). Evaluation of different fungal strains in the decolourisation of synthetic dyes. Biotechnology Letters, 22, 1499.

Moreira, M.T., Palma, C., Mielgo, I., Feijoo, G. and Lema, J.M. (2001). In vitro degradation of polymeric dye (Poly R-478) by manganese peroxidase. Biotechnology \& Bioengineering, 75, 362.

O’Neill, C., Hawkes, F., Hawkes, D., Laurenco, N., Pinheiro, H. and Delée, W. (1999). Colour in textile effluents sources measurement, discharge consents and simulation: a review. Journal Chemistry Technology Biotechnology, 74, 1009.

Palma, C., Moreira, M.T., Feijoo, G. and Lema, J.M. (1997). Enhanced catalytic properties of MnP by exogenous addition of manganese and hydrogen peroxide. Biotechnology Letters, 19, 263.

Palma, C. (1998). Caracterización cinética de MnP de Phanerochaete chrysosporium y Bjerkandera sp. BOS55 y Aplicación a la decoloración de efluentes industriales. Tesis Doctoral, Universidad de Santiago de Compostela.

Palma, C., Moreira, M.T., Mielgo, I., Feijoo, G. and Lema, J.M. (1999). Use of a fungal bioreactor as a pretreatment or post-treatment step for continuous decolourisation of dyes. Water Science Technology, 40, 131.

Robinson, T., McMullan, G., Marchant, R and Nigam, P. (2001). Remediation of dyes in textile effluent: a critical review on current treatment technologies with proposed alternatives. 
Bioresource Technology, 77, 247.

Sani, R.K. and Banerjee, U.C. (1999). Decolorization of triphenylmethane dyes and textile and dye-stuff effluent by Kurthia $s p$. Enzyme Microbiology Technology, 24, 433.

Spadaro, J.T., Gold, M.H. and Renganathan, V. (1992). Degradation of azo dyes by the lignindegrading fungus Phanerochaete chrysosporium. Applied Environmental Microbiology, 58, 2387.

Tien, M. and Kirk, T.K. (1988). Lignin peroxidase of Phanerochaete chrysosporium. In: Wood, W.A. and Kellog, S.T. (Eds.) Methods Enzymology, Academic Press, San Diego C.A 161, 238.

Wariishi, H., Akileswaran, L. and Gold, M.H.
(1988). Manganese peroxidase from the basidiomycete Phanerochaete chrysosporium: Spectral characterization of the oxidized states and the catalytic cycle. Biochemistry, 27, 5365.

Yang, Q., Yang, M., Pritsch, K., Yediler, A., Hagn, A., Schloter, M. and Kettrup, A. (2003). Decolorization of synthetic dyes a production of manganese-dependent peroxidase by new fungus isolates. Biotechnology Letters, 25, 709.

Zhang, S.J., Yang, M., Yang, Q.X., Zhang, Y., Xin, B.P. and Pan, F. (2003). Biosorption of reactive dyes by the mycelium pellets of a new isolates of Penicillium oxalicum. Biotechnology Letters, 25, 1479. 